\title{
Assessment of Insecticide/Miticide Treatments on Soybean Cyst Nematode Bioassays Under Greenhouse Conditions
}

\author{
Jordan Brungardt, Timothy C. Todd, Thomas R. Oakley, and Harold N. Trick ${ }^{\dagger}$ \\ Department of Plant Pathology, Kansas State University, Manhattan, KS 66502
}

Accepted for publication 12 March 2019.

Keywords: pesticides, soybean cyst nematode, soybean, bioassay

Soybean cyst nematodes (SCNs) (Heterodera glycines, Ichinohe) are a plant parasite that impacts soybean (Glycine max Merr.) yields in all major soybean producing countries (Wrather et al. 2010). This obligatory parasite feeds on soybean roots, diverting energy away from plant biomass and seed production. After mating and producing eggs, female SCNs turn into hard, durable cysts, which allows their eggs to survive in the soil for many years before infecting a new plant (Porter et al. 2001). Despite the large amount of information known about this pathosystem, research continues with the aim of developing resistance through conventional breeding and biotechnology. An integral part of this research happens in the controlled environment of greenhouses in scaled-down bioassays. Soybeans grown under greenhouse conditions are often burdened with chronic infestations of plant pests such as aphids, spider mites, white flies, and thrips. The use of pesticides is a common method for keeping such pests under control. Unfortunately, rotating through a variety of pesticides with different modes of action (MoAs) is required to prevent pesticide resistance from developing in insect populations. This research examines the possibility of insecticides and miticides interfering with SCN female, cyst, egg, and second-stage juvenile (J2) numbers either through direct contact with runoff or encountering systemic pesticides when feeding.

Previously, Brady et al. (2012) showed several pesticides to be compatible with SCN bioassays. The aim of this study was to broaden that spectrum by evaluating pesticides with three MoAs not previously tested (active ingredients: bifenthrin, pyridaben, and S-kinoprene), a MoA of new chemistry (clofentezine), and a soilapplied, imidacloprid-based insecticide. All pesticides used in this study are given in Table 1. Although a 10A MoA has been previously tested for interactions with SCNs (Brady et al. 2012), molecular targets for chemicals in this group are yet to be defined (Sparks and Nauen 2015). The 10A MoA active ingredient tested here, clofentezine, has a strikingly different chemical structure compared with that of the hexythiazox-based insecticide tested by Brady et al. (2012). Several previously tested pesticides were also included in this study as comparative checks to previous work (abamectin and imidacloprid).

\section{${ }^{\dagger}$ Corresponding author: Harold N. Trick; E-mail: hnt@ksu.edu}

This article is contribution no. 19-057-J from the Kansas Agricultural Experimental Station, Kansas State University, Manhattan, KS.

Funding: This research was supported by the Kansas Soybean Commission.

The author(s) declare no conflict of interest.

(C) 2019 The American Phytopathological Society
Combinations of S-kinoprene or clofentezine with foliar-applied imidacloprid were also tested. Although none of the pesticides tested here are marketed as having nematicidal effects, abamectin and other avermectins are well known for having inhibitory effects on nematodes, including human parasites and nematodes that are closely related to $\mathrm{SCN}$ such as root knot nematodes (Meloidogyne sp.) (Cabrera et al. 2009; Sasser and Kirkpatrick 1982). Furthermore, toxicological studies have shown that all the active ingredients used in this study, except kinoprene (not tested), have inhibitory effects on the model nematode Caenorhabditis elegans (Boyd et al. 2016). These reports raise concern as to whether these pesticides can be safely used on SCN bioassays without interference to the nematode.

To test for interference of insecticides and miticides on SCN bioassays, three seeds of the susceptible soybean cultivar KS3406 were planted into D40 Deepots (Stuewe and Sons, Tangent, OR) containing $450 \mathrm{~cm}^{3}$ of a sand-soil mixture infested with $\mathrm{Hg}$ type 7 population eggs at an initial population density of 2,560 eggs per $100 \mathrm{~cm}^{3}$. The inoculum was obtained by rearing an $\mathrm{Hg}$ type 7 field isolate on KS3406 for 8 to 10 weeks. Plants emerging from a single tube were treated as a single observational unit. A randomized complete block design structure was employed using three blocks, with each block having three repeated measures per treatment. Granular imidacloprid was applied once after plant emergence. For other treatments, plants were sprayed with pesticides every 10 days after planting, three times total with a hand-pump sprayer. Between each treatment the sprayer was rinsed and the hose purged with tap water three times. Control plants were sprayed with tap water. Pesticides were applied at the manufacturer's recommended application rate. Plants were sprayed until leaves were uniformly

\section{TABLE 1}

Pesticides evaluated for interference with soybean cyst nematode bioassays including trade name, active

ingredient, and the Insecticide Resistance Action Committee mode of action classification (MoA)

\begin{tabular}{llll} 
Trade name & $\begin{array}{c}\text { Active } \\
\text { ingredient }\end{array}$ & MoA & \multicolumn{1}{c}{ Manufacturer } \\
Avid & Abamectin & 6 & Syngenta (Greensboro, NC) \\
Sanmite & Pyridaben & 21A & Gowan Comp. (Yuma, AZ) \\
Talstar P & Bifenthrin & 3A & FMC Corp. (Philadelphia, PA) \\
Marathon II & Imidacloprid & 4A & OHP, Inc. (Mainland, PA) \\
Marathon 1\% & Imidacloprid & 4A & OHP, Inc. (Mainland, PA) \\
$\quad$ granular & & & \\
Enstar II & S-Kinoprene & 7A & Wellmark (Schaumburg, IL) \\
Ovation SC & Clofentezine & 10A & Scotts (Marysville, OH)
\end{tabular}


covered. Soil was not protected from overspray or run-off of pesticides. Roots were harvested 35 days after plant emergence. Female nematodes, cysts, eggs, and J2s were harvested as described in Brady et al. (2012). The experiment was conducted under greenhouse conditions in June 2016 and repeated in August of the same year. Greenhouse day/night temperatures were maintained at $27 / 22 \pm 2{ }^{\circ} \mathrm{C}$, and natural lighting was augmented with $16 \mathrm{~h}$ of sodium growth lamps. Nematode counts were normalized against total grams of dry root weight per pot. Data were analyzed with SAS software, version 9.4 for Windows, using the GLIMMIX procedure. A log-normal distribution was used to reduce heterogeneity of variance. Post hoc analyses of treatment means were conducted using Dunnett's procedure for comparing multiple treatment means with the control $(P \leq 0.05)$.

No significant differences were found in female + cyst counts or egg $+\mathrm{J} 2$ production for pesticide treatments against control plants (Fig. 1). The smallest $P$ value for female + cyst counts compared with the control group was that of bifenthrin (Dunnett adjusted $P$ value $=$ 0.237). The smallest $P$ value for egg $+\mathrm{J} 2$ counts was that of imidacloprid (Marathon II) (Dunnett adjusted $P$ value $=0.487$ ). Absolute mean densities of SCN females + cysts and eggs + second-stage juveniles for each treatment are given in Table 2. In general, numbers

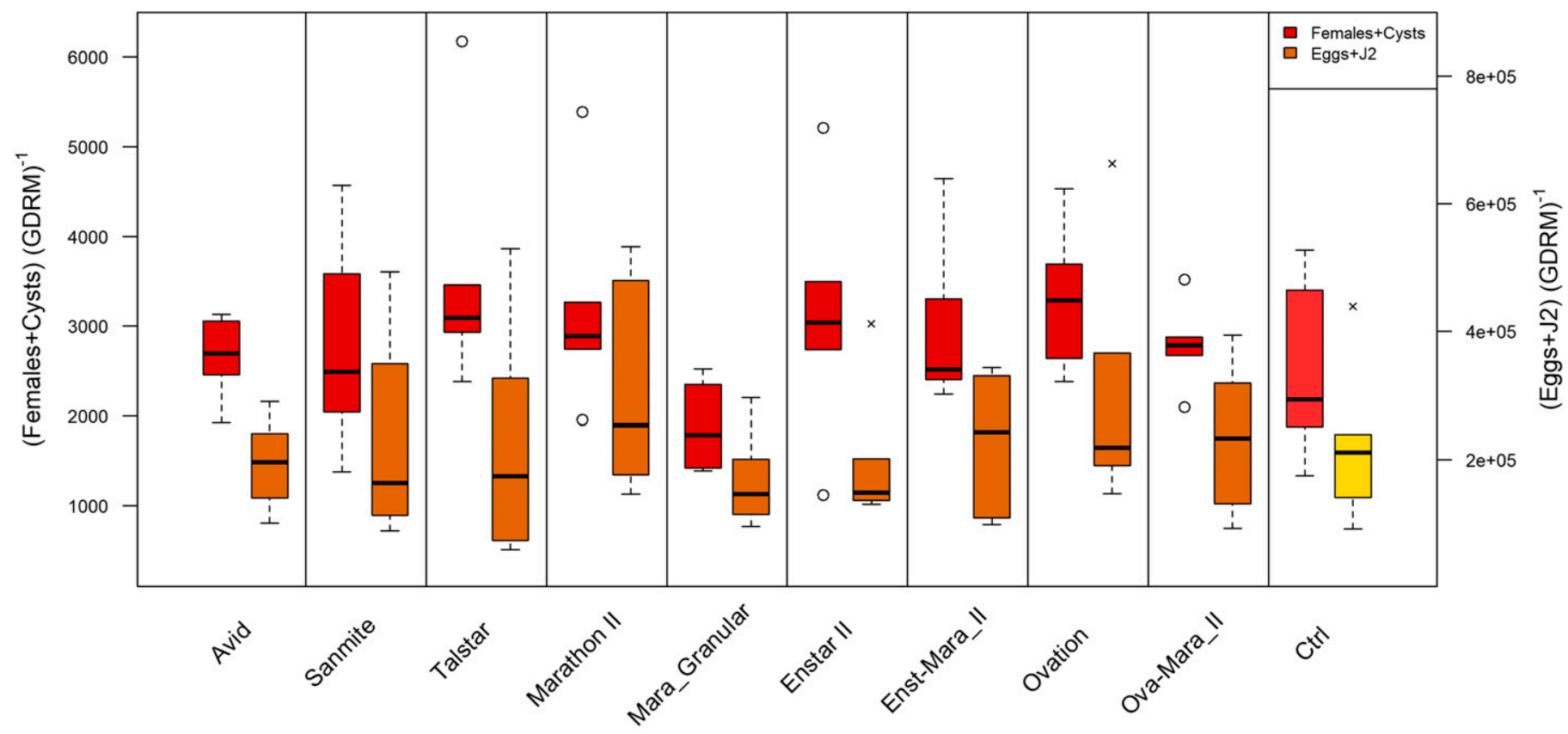

Pesticide Treatment

\section{FIGURE 1}

Boxplot of soybean cyst nematode female + cyst and egg + second-stage juvenile (J2) counts per gram of dry soybean root in pots treated with insecticides and miticides encompassing six modes of action. Dunnett's test showed no significant differences when comparing pesticide treatments to water control for female + cyst or egg $+\mathrm{J} 2$ counts. Boxes represent first and third quartiles, and lines in boxes represent treatment medians. Whiskers represent the minimum of either 1.5 times the interquartile range or the extreme of the sample range. Circle $(O)$ indicates female + cyst outliers, and $\times$ indicates egg $+J 2$ outliers. GDRM $=$ grams dried root mass; $\mathrm{Ctrl}=$ negative control; $\mathrm{Enst}=$ Enstar; Mara = Marathon; and Ova = Ovation.

\begin{tabular}{|c|c|c|c|c|}
\hline Absolute mean de & $\begin{array}{l}\text { cyst } \\
\text { ith ins }\end{array}$ & $\begin{array}{l}\text { TABLE } 2 \\
\text { les + cysts anc } \\
\text { iticides encom }\end{array}$ & $\begin{array}{l}\text { stage jur } \\
\text { es of act }\end{array}$ & oybean roots \\
\hline & & //GDRM & & RM \\
\hline Treatment & Mean & Standard error & Mean & Standard error \\
\hline Ovation & 3,303 & 314 & 300,609 & 78,510 \\
\hline Enstar II & 3,107 & 537 & 195,896 & 44,412 \\
\hline Marathon II & 3,188 & 475 & 306,773 & 66,244 \\
\hline Sanmite & 2,758 & 469 & 228,368 & 65,951 \\
\hline Talstar & 3,521 & 550 & 222,756 & 73,368 \\
\hline Enstar-Marathon II & 2,936 & 373 & 227,714 & 45,798 \\
\hline Ovation-Marathon II & 2,789 & 186 & 233,510 & 46,442 \\
\hline
\end{tabular}

\footnotetext{
${ }^{\mathrm{a}} \mathrm{GDRM}=$ grams dried root mass
} 
of females and cysts per gram of dried root mass were higher than that of the control group. The granular imidacloprid treatment group was the only exception to this, averaging 597 fewer females + cysts per gram of dried root mass. There was no particular pattern to pesticide treatment means compared with the control group regarding egg + $\mathrm{J} 2$ numbers produced per gram of dried root mass. Because no significant differences were found between pesticide treatments and the control group, pesticides evaluated in this study should be considered safe to use with SCN bioassays at an application frequency of 1.5 weeks, as well as less frequent application rates owing to chemical degradation under greenhouse conditions.

\section{Literature Cited}

Boyd, W. A., Smith, M. V., Co, C. A., Pirone, J. R., Rice, J. R., Shockley, K. R., and Freedman, J. H. 2016. Developmental effects of the ToxCast ${ }^{\mathrm{TM}}$ phase I and phase II chemicals in Caenorhabditis elegans and corresponding responses in zebrafish, rats, and rabbits. Environ. Health Perspect. 124:586-593.

Brady, C. R., Li, J. L., Todd, T. C., Oakley, T. R., and Trick, H. N. 2012. Compatibility of foliar insecticides and soybean cyst nematode bioassays. Plant Health Progress 13. doi: 10.1094/PHP-2012-0409-01-BR

Cabrera, J. A., Kiewnick, S., Grimm, C., Dababat, A. A., and Sikora, R. A. 2009. Efficacy of abamectin seed treatment on Pratylenchus zeae, Meloidogyne incognita and Heterodera schachtii. J. Plant Dis. Prot. 116:124-128.

Porter, P. M., Chen, S. Y., Reese, C. D., and Klossner, L. D. 2001. Population response of soybean cyst nematode to long term corn-soybean cropping sequences in Minnesota. Agron. J. 93:619-626.

Sasser, J. N., and Kirkpatrick, T. L. 1982. Efficacy of avermectins for root-knot control in tobacco. Plant Dis. 66:691-693.

Sparks, T. C., and Nauen, R. 2015. IRAC: Mode of action classification and insecticide resistance management. Pestic. Biochem. Physiol. 121:122-128.

Wrather, J. A., Shannon, G., Balardin, R., Carregal, L., Escobar, R., Gupta, G. K., Ma, Z., Morel, W., Ploper, D., and Tenuta, A. 2010. Effect of diseases on soybean yield in the top eight producing countries in 2006. Plant Health Progress 11. doi: 10.1094/PHP-2010-0102-01-RS 